\title{
Adoption and Diffusion of Agroecological Practices in the Horticulture of Catalonia
}

\author{
Adrián Polonio Punzano ${ }^{1, *}$, Djamel Rahmani ${ }^{2} \mathbb{D}$ and Maria del Mar Cabello Delgado ${ }^{1}$ \\ 1 Escola Tècnica Superior d'Enginyeria Agrària (udl), Universitat de Lleida, Av. de l'Alcalde Rovira Roure 6 \\ 191, 25199 Lleida, Spain; mdmarcabello@gmail.com \\ 2 Centre de Recerca en Economia i Desenvolupament Agroalimentari (CREDA-UPC-IRTA), \\ Universidad Politécnica de Barcelona, 08860 Barcelona, Spain; djamel.rahmani@upc.edu \\ * Correspondence: agroadri97@gmail.com; Tel.: +34-638-24-7894
}

check for

updates

Citation: Polonio Punzano, A. Rahmani, D.; Cabello Delgado, M.d.M. Adoption and Diffusion of Agroecological Practices in the Horticulture of Catalonia. Agronomy 2021, 11, 1959. https://doi.org/ 10.3390/agronomy11101959

Academic Editors: Riccardo Testa, Giuseppina Migliore,

Giorgio Schifani and József Tóth

Received: 20 September 2021

Accepted: 28 September 2021

Published: 29 September 2021

Publisher's Note: MDPI stays neutral with regard to jurisdictional claims in published maps and institutional affiliations.

Copyright: (c) 2021 by the authors. Licensee MDPI, Basel, Switzerland. This article is an open access article distributed under the terms and conditions of the Creative Commons Attribution (CC BY) license (https:// creativecommons.org/licenses/by/ $4.0 /)$.

\begin{abstract}
The environmental impact of conventional food production systems imposes a rapid transition towards sustainable production systems through the adoption of agroecological practices. The barriers and accelerators of the adoption of agroecological practices were identified for horticultural crops in Catalonia. Eight interviews and thirty surveys were conducted with local producers. Results show that the loss of producer income and the lack of social awareness regarding organic products are among the important barriers to the adoption of agroecological practices, while information about the experience of other farmers is considered a motivational factor. Finally, the study concludes that the adoption of agroecological practices has economic, political, social, academic and agronomic components.
\end{abstract}

Keywords: agroecological practices; barriers; accelerators; farmers' adoption

\section{Introduction}

Agroecology is a type of agriculture which appeared at the end of the last century with the objective of providing an alternative to conventional agriculture (that is, agriculture which favors destruction of the circular economy and the loss of biodiversity [1]). Hallmarks of organic farming include: the use of biological control to treat pests and diseases, and of organic amendments, livestock and/or plant remains to fertilize the fields; direct seeding or minimum tillage to reduce the loss of soil through erosion and increase biodiversity, soil fertility and the content of organic matter in the soil; increased crop application of coverage and use of microorganisms to help the plant absorb nutrients in the soil with greater ease, in order to strengthen the plant against pests and diseases and thus increase yields; and application of genetics to extract more climate-resistant cultivable species with high yields under changing climatic conditions involving drought, saline soils, pests and diseases, etc. In addition, the application of genetics allows for diversification and crop rotation, which are the two fundamental pillars of agroecology.

According to Róger [2], agroecology is a scientific discipline which gathers, synthesizes and applies knowledge from agronomy, ecology, sociology and ethnobotany, and with a holistic and systemic ethics; therefore, it is an agricultural system which provides a rational ecological base for the management of the agroecosystem through innovative production technologies, stable and highly adaptable to the environment and society. Wezel et al. [3] classified agroecological practices according to the level of integration that the crops have and depending on the degree of implementation they have. According to them, the integration of organic fertilization, cover crops, irrigation by drip and biological pest control, among others, have already reached an average level of integration into current agriculture and have high potential for wider application in the next decade, already benefiting from a good scientific knowledge; however, the integration of allelopathic plants, biofertilizers, agroforestry systems and the management of landscape elements at scale 
have a low level of integration, and will not be easily implemented in the field in the near future, as these rely on a larger scale of management and largely on the regional and national general conditions which are subject to project framework and territorial development planning.

This article shows how agroecology affects the social, economic, environmental, political, ethical and cultural aspects. At the social level, agroecology aims to configure a system which values the food sovereignty of producers and reinforces the health and well-being of present and future generations of farmers and independence and autonomy in their development, participation and decision-making. In the field of economics, agroecology assumes that the associated benefits make it possible to cover the needs of the producer and reduce the risks associated with dependence on markets, inputs or low product diversification; it makes efficient use of goods, services, production and equitable distribution, without damaging the renewal, reproduction and distribution of the agroecosystem. In the same way, politics analyzes and act on social conditions, networks and conflicts resulting from the support for sociocultural agroecological change, with a view to achieve a sustainable social or socio-vital metabolism, which affects the construction of styles of food (patterns and networks of production, distribution and consumption) and equitable and sustainable democratization of food. Finally, agroecology understands that at an ethical and cultural level, humans should reduce their excessive food consumption and environmental degradation and incorporate ancestral and character values and knowledge in order to eliminate hunger, poverty and negative consequences for the environment, and that farmers should decide to modify natural ecosystems to transform them into agroecosystems through the choice and distribution of spontaneous crops, animals and plants considering their values, beliefs and objectives.

Over the last few years and coinciding with what Gil et al. [4] reported, consumers, companies and administrations have been becoming aware of issues related to food safety and environmental problems. Consumers' concern for food safety has increased sensitivity to environmental degradation. That is why their conscience and behaviors (which are closely related to ecology) have been taking a center stage in such a manner that they try to make their actions less damaging to the environment. The tendency to purchase organic products is influenced by demographic, socioeconomic, psychographic and behavioral variables. All of them explain in different studies why consumers, companies and institutions are committed to buying and selling organic products [5,6]. Díaz et al. [7] found that consumer lack of information and knowledge as well as high prices are the most relevant barriers to the consumption of organic food. Grymshi et al. [8] analyzed consumer' purchasing behavior towards ecolabeled food products and based on the degree of familiarity and consumption patterns, they identified three typologies of consumers including indifferent, committed, and skeptical. At the European level, age is a very important factor when buying organic products. The people who are more interested in purchasing organic products are between 15-55 years of age [9]. In particular, $26 \%$ of this segment are people under 35 years old, while $76 \%$ are above 35 [10].

Agriculture in general is undergoing a change at the social, economic, political and environmental levels which requires farmers and ranchers to adopt more sustainable agricultural practices and methods. This will force the transition from a polluting conventional agriculture characterized by excessive use of chemical inputs (fertilizers, pesticides, etc.) to a green agriculture, efficient, profitable and socially, economically and environmentally sustainable. This reality is reflected in the great interest shown by the scientific community (Brzozowski and Mazourek, 2018; Keulmans, 2019; Clark and Tilman, 2017) in assessing the economic, social and environmental conditions of agriculture in recent years. However, despite social pressure, environmental awareness, warnings from national and international environmental organizations and public support, with favorable policies and programs, the rate of adoption of agroecological practices among farmers and ranchers continues to be very low, as reflected by the low presence of organic products in the market. The objectives of the present work are: (i) to make a diagnosis on the diffusion of agroecolog- 
ical practices in the horticulture of Catalonia; (ii) to assess farmers' intentions to adopt agroecological practices; (iii) to describe the profile of potential adopters of agroecological practices; and (iv) to understand the most relevant barriers and drivers. To reach these objectives, interviews and surveys were conducted among a group of farmers in Catalonia.

Literature showed that the adoption of agroecological practices is determined by a series of barriers and motivations [11]. Horrillo et al. [12] showed how organic farms are not economically profitable for farmers. Horrillo et al. [13] also reported that organic livestock farms could be economically remunerated for the ecosystem services they provide to society, especially when their net $\mathrm{CO}_{2}$ balance is negative. Dessart et al. [14] classified the behavioral factors that affect the decision to adopt or not adopt agroecological practices as dispositional (personality, motivations, values, beliefs, preferences, goals), social (interactions, social norms, signaling motives) and cognitive (learning, reasoning, perceptions of benefits, costs and risks). Pearce et al. [15] and Damalas et al. [11] indicated that the variation in pesticide use among farmers is associated with a set of factors including low level of internal inputs, market demand, the presence of pests and diseases, the need to produce food in abundance, the pursuit of the greatest financial benefit, the adoption of methods of organic farming, the efficacy of pesticides, and concerns about pesticide exposure and environmental pollution. Horrillo et al. [16] identified the stagnation of sales, the lack of self-sufficiency in organic feed and the difficulty of access to organic certified slaughterhouses as relevant barriers to the transition from a conventional farm to an organic system.

Runhaar et al. [17] identified age, sex, social and educational level, knowledge and experience of the farmer, as well as the size of the farm as variables which affect the willingness of farmers to adopt innovative practices. Hashemi and Damalas [18] highlighted the importance of such factors as the perception of pesticide safety and knowledgeable experience of pest integration methods in the decision of farmers to adopt or not adopt alternatives to conventional agricultural practices.

Other authors [17] highlighted the role of factors such as motivations, information, social context, government agreements, demand, particular skills and abilities of implementation, legitimization, the holistic framework which integrates personal and contextual factors, and the multidisciplinary framework (nature conservation and factors that stimulate behavior change) in the decision to adopt sustainable alternatives by farmers. For example, some authors $[19,20]$ investigated farmers' intention to adopt new soil conservation practices focusing on variables such as biophysical, economic, social, regulatory and institutional conditions (Table 1).

To adopt a new practice, a farmer should be sure of the steps he or she is going to take, so he or she should know if he or she can receive financial aid, if the crop is going to be profitable [21] and should also know the new practices and products. He or she also needs to have knowledge, awareness, attitude and perception of the risks associated with these practices [22]. Another very important factor is the prior adoption of ecological practices by other farmers who can positively influence those who have not yet taken the decision to switch to agroecological practices.

Table 1. Barriers and Solutions.

\begin{tabular}{cccc}
\hline Authors & Subject & Barriers & Solutions \\
\hline Valerio et al., (2016) & $\begin{array}{c}\text { Conservation agriculture } \\
\text { (Mexico) }\end{array}$ & $\begin{array}{c}\text { Business orientation; The short term } \\
\text { expected objectives; The economic } \\
\text { limitations. }\end{array}$ & $\begin{array}{c}\text { Invest in: cultivar development } \\
\text { adapted to the environment } \\
\text { and/or resistant to pests and } \\
\text { diseases; plant breeding; }\end{array}$ \\
Brzozowski and & $\begin{array}{c}\text { Organic plague } \\
\text { management }\end{array}$ & $\begin{array}{c}\text { Biological complexity due to having } \\
\text { difficulty in accessing data and concepts. }\end{array}$ & $\begin{array}{c}\text { understanding and promotion of } \\
\text { plant-relations rhizosphere. }\end{array}$ \\
\hline
\end{tabular}


Table 1. Cont.

\begin{tabular}{|c|c|c|c|}
\hline Authors & Subject & Barriers & Solutions \\
\hline $\begin{array}{l}\text { Schoonhoven and } \\
\text { Runhaar (2018) }\end{array}$ & $\begin{array}{l}\text { Adoption of } \\
\text { agroecological practices: } \\
\text { holistic frame }\end{array}$ & $\begin{array}{c}\text { Absence of commercial models; } \\
\text { Structural difficulty / barrier } \rightarrow \text { difficulties } \\
\text { to find funds. }\end{array}$ & \\
\hline $\begin{array}{l}\text { Hashemi and } \\
\text { Damalas (2011) }\end{array}$ & $\begin{array}{c}\text { Farmer perceptions } \\
\text { towards the plaguicide } \\
\text { efficiency }\end{array}$ & $\begin{array}{l}\text { Beliefs, perceptions and preferences; } \\
\text { Scarcity of technical and advisory } \\
\text { support. }\end{array}$ & \\
\hline $\begin{array}{l}\text { Bijttebier et al., } \\
\qquad(2014)\end{array}$ & $\begin{array}{c}\text { Adoption of } \\
\text { conservation practices in } \\
\text { Europe }\end{array}$ & $\begin{array}{l}\text { Changes in economic conditions after } \\
\text { adoption; Lack of adequate machinery; } \\
\text { Presence of the plow; Soil texture } \\
\text { (compaction); Slope; legislation; nature of } \\
\text { crops; Yields (decrease); Lack of } \\
\text { stimulation. }\end{array}$ & $\begin{array}{l}\text { Understand the differences } \\
\text { between countries when adopting } \\
\text { practices for soil conservation; } \\
\text { Informing people or institutions. }\end{array}$ \\
\hline Pearce et al., (2019) & $\begin{array}{l}\text { Promotion of } \\
\text { alternatives to } \\
\text { plaguicides }\end{array}$ & $\begin{array}{l}\text { Lack of training (and knowledge); } \\
\text { Difficulties accessing the network. }\end{array}$ & $\begin{array}{l}\text { Alternatives to the use of } \\
\text { pesticides: Train the farmers; } \\
\text { Educate the young students } \\
\text { through practical classes with the } \\
\text { help of technology. }\end{array}$ \\
\hline Malina et al., (2019) & $\begin{array}{l}\text { Disposition and } \\
\text { perception to pay for } \\
\text { bioplaguicides }\end{array}$ & $\begin{array}{l}\text { Literature shortage; The perceived risk; } \\
\text { the price of the biopesticide; High } \\
\text { perception of pesticide efficacy. }\end{array}$ & $\begin{array}{l}\text { Introduce definitions of pesticides } \\
\text { and biopesticides in the } \\
\text { interviews; Perform } \\
\text { communication efforts } \\
\text { (campaigns of information and } \\
\text { education). } \\
\text { For sustainable agriculture: } \\
\text { Development of techniques to } \\
\text { reduce negative impact of } \\
\text { chemical inputs; Implementation } \\
\text { of a legal framework; The } \\
\text { contribution of consumers; More } \\
\text { research to understand needs, } \\
\text { motivations or factors that hinder } \\
\text { the consumption of sustainable } \\
\text { products; Conduct studies taking } \\
\text { into account the intensity of the } \\
\text { willingness to pay. }\end{array}$ \\
\hline Dessart et al., (2019) & $\begin{array}{l}\text { Factors affecting the } \\
\text { adoption of agrological } \\
\text { sustainable: politics. }\end{array}$ & $\begin{array}{l}\text { Group behavior; Resistance to change; } \\
\text { Difficulty in policy agricultural } \\
\text { segmentation; Treat all farmers the same; } \\
\text { Lack of knowledge of sustainable } \\
\text { agriculture practices by the citizen; Lack } \\
\text { of Knowledge } \rightarrow \text { Lack of participation; } \\
\text { Greater fluctuation in demand and the } \\
\text { offer of organic production; Prohibition } \\
\text { of the use of chemical fertilizers or } \\
\text { synthetic pesticides } \rightarrow \text { increases the risk of } \\
\text { failure of crops; The variability of the soil } \\
\text { reaction to sustainable practices and } \\
\text { uncertain efficacy of sustainable practices; } \\
\text { Uncertainty; financial risks. }\end{array}$ & $\begin{array}{l}\text { Segment farmers indirectly } \\
\text { according to: age, sex and country } \\
\text { or region; Design a combination } \\
\text { of policies based on voluntary } \\
\text { adoption and mandatory } \\
\text { sustainable practices; design } \\
\text { subsidized environmental } \\
\text { schemes. } \\
\text { Policy tools to decrease Perceived } \\
\text { risks: offering Insurance; } \\
\text { Promotion of mutual funds; } \\
\text { Promotion of free practice } \\
\text { sustainable tests. }\end{array}$ \\
\hline
\end{tabular}


Table 1. Cont.

\begin{tabular}{|c|c|c|c|}
\hline Authors & Subject & Barriers & Solutions \\
\hline Keulemans (2019) & $\begin{array}{l}\text { Can we grow without } \\
\text { the use of herbicides, } \\
\text { fungicides and } \\
\text { insecticides? }\end{array}$ & $\begin{array}{l}\text { For increased performance: acidification; } \\
\text { The loss of biodiversity; Soil erosion; the } \\
\text { eutrophication of superficial water. } \\
\text { Reduction of active substances } \rightarrow \text { higher } \\
\text { resistances } \rightarrow \text { decrease in the effectiveness } \\
\text { of the products } \rightarrow \text { higher losses. } \\
\text { Longer time required to get a new } \\
\text { product; Sub-optimal factors: fertilizers, } \\
\text { adapted varieties, irrigation, other } \\
\text { techniques of crops; Difficulty relating } \\
\text { the use of phytosanitary products with } \\
\text { performance through experimental and } \\
\text { quantitative data; Unclear and imprecise } \\
\text { media communication; Lack of } \\
\text { knowledge of diseases or pests and of the } \\
\text { impact of these by agronomists, advisers } \\
\text { or farmers; The MIP incorporates a wide } \\
\text { range of practices, but does not establish } \\
\text { explicitly the degree of reduction of APP } \\
\text { at farm level; Little/Low accuracy on } \\
\text { whether the greater biodiversity in } \\
\text { organic agriculture is due to the } \\
\text { management of biopesticides or the low } \\
\text { performance. }\end{array}$ & $\begin{array}{l}\text { To bridge the gap: Promote } \\
\text { sustainable intensification of } \\
\text { agriculture; reduce losses and } \\
\text { food waste; Change diet; Prohibit } \\
\text { crop production for bioenergy; } \\
\text { Give an optimized use of } \\
\text { phytosanitary products. }\end{array}$ \\
\hline
\end{tabular}

Low acceptance of training on pesticides and job aging; Limited studies on the relevance and effectiveness of the training; Lack of educational guides for treating the destruction of beneficial

Damalas and Koutroubas (2017)
The training in the use of pesticides associated to safety behavior insects; Problems: Spray more often and at a higher dose; Factors (1 and 2) to evaluate the training by any means available: The decision making (1) and To design most effective training components (2).
Clark and Tilman

(2017)
Comparative Analysis of environmental impacts of the system of agricultural production, efficiency of the agricultural inputs and choice of food.
The limitation focused on food of animal origin or a single environmental indicator; the comparative environmental impacts of control practices with a lower use of pesticides.
Increase awareness of alternative pest control practices with less pesticide use.
Apply management technologies and techniques to increase the efficiency of agricultural inputs through: agriculture of precision, conservation tillage and cover crop, feed intake in livestock systems: use of agricultural waste and by-products; Interventions to reduce future environmental impact aspects of agriculture: adoption of low-meat diets in countries with excessive meat consumption, increase sustainable yields of crops and reduce waste of food; Implementation of initiatives and policies in education designed to increase the adoption of low-fat food impacts, of less impact on production systems and systems with high efficiency of agricultural inputs. 
Table 1. Cont.

\begin{tabular}{|c|c|c|c|}
\hline Authors & Subject & Barriers & Solutions \\
\hline Damalas et al., (2018) & $\begin{array}{l}\text { Criteria for the selection } \\
\text { and use of pesticides }\end{array}$ & $\begin{array}{l}\text { Little evidence on use of pesticides } \\
\text { patterns; Limited information; Technique } \\
\text { limitations; Little research on nature of } \\
\text { farmers' criteria for selection and use } \\
\text { pesticides; Reduction of subsidies; } \\
\text { Limited knowledge of allowed amounts } \\
\text { of pesticides; Low levels of education and } \\
\text { training in management of pesticides; } \\
\text { Ineffectiveness of training courses. }\end{array}$ & \\
\hline Kragt et al., 2017 & $\begin{array}{l}\text { Motivations and barriers } \\
\text { so that large extension } \\
\text { land Occidential } \\
\text { Australian agricultures } \\
\text { adopt carbon agriculture }\end{array}$ & $\begin{array}{l}\text { For participation: The complexity of the } \\
\text { scheme (amount of paperwork involved } \\
\text { for becoming a registered provider); the } \\
\text { strict program rules (requirements for } \\
\text { permanence); Information limitations. }\end{array}$ & \\
\hline
\end{tabular}

\section{Materials and Methods}

In this work, two research techniques were combined including a qualitative method (interviews) and a quantitative technique (questionnaire). The purpose of the interviews with the farmers was to extract ideas which would feed the preparation of the questionnaire. In total, eight farmers were interviewed in the province of Barcelona. The farmers interviewed mostly practiced traditional horticulture. Three of the eight farmers were engaged in fruit growing; two were from conventional agriculture and one from ecological agriculture. The interviews were planned to be conducted physically in the field; however, we were forced to carry out these interviews via telephone due to the restrictions imposed by the authorities to reduce the propagation of COVID-19.

Based on the interviews and the literature review, a first survey was carried out as a pilot test. The pilot test was carried out with ten farmers from different sectors in order to correct errors, refine the questions, and identify important aspects not included in order to take them into consideration, as well as to estimate the average time required to complete the survey. Subsequently, we proceeded to the realization and shipment (via email) of the final survey. For data collection, we proceeded to contact farmers, companies and public and private institutions in the agri-food sector such as cooperatives, ADVs (Groups of Plant Defense of Catalonia), associations and universities. It took two months to collect the 30 surveys. This delay was due to the fact that the months of collecting data coincided with the full harvest period.

The interview script consisted of open or semi-open questions. For example, the first question consisted of finding out the characteristics of the farm and the farmer (cultivable hectares, farmer's age, number of family members who are engaged in agricultural exploitation, number of workers, etc.) and what type of agriculture they practice and the type of crops they cultivate. The following questions were dedicated to extracting information about whether they adopted (or not) agroecological practices and why. To do this, they were asked directly if they had ever adopted any agroecological practice and what type, and if they had done it with or without aid, what type of barriers and/or motivations they had in adopting these practices, if they plan to adopt (or not) agroecological practices in the future and why. Finally, we asked them whether they will continue using the same production system after the COVID-19 crisis or if they plan to switch to agroecological or more sustainable practices and why.

The survey was designed focusing on aspects related to the adoption (or not) of agroecological practices by farmers (conventional and/or organic) and what factors affect this adoption. The survey was divided into 11 sections: (1) Characteristics of the farm; (2) Agroecological practices adopted until now; (3) Barriers to agroecological practices;

(4) Accelerators of the adoption of agroecological practices; (5) Perception of the benefits 
of agroecological practices; (6) Intention to adopt agroecological practices in the future; (7) Trust in the different sources of information on agroecological practices; (8) Attitudes (preferences) to risk; (9) Attitudes towards the environment; (10) Perception of exposure to and risk from chemicals; and (11) Sociodemographic characteristics.

To measure the Attitudes towards the environment, we used the new reduced version of the Ecological Paradigm scale (NEP-R). Farmers were required to indicate their level of agreement with the statements in a 5-point scale (from 1 'Strongly disagree' to 5 'Strongly agree'). This scale allowed us to segment farmers into ecocentric and/or anthropocentric groups.

Data analysis was performed with the SPSS statistical program. We started with some descriptive analyses, which we represented in figures and tables. A factor analysis was carried out with the objective of reducing the elements of the environmental attitudes scale (NEP-R). Finally, bivariate analyses were carried out to describe the relationship between the variable "intention to adopt agroecological practices in the future" and various characteristics of the farmers and their farms, in order to identify the profile of potential adopters of agroecological practices in the future. The relationships between the variables are represented in figures. These analyses were performed using statistical tests (analysis of variance and Tukey) in order to detect which groups of farmers were more susceptible to adopting agroecological practices. It was not possible to conduct some multivariate analyses due to small size of the sample we used.

\section{Results}

The results are presented in the following way: first we describe the results from the interviews, then we reported the results from the surveys. Those from the surveys are divided into the following sections: (1) Characteristics of farmers and their farms; (2) Level of knowledge, perceptions and farmers' attitudes towards pesticides and agroecological practices; (3) Main barriers, accelerators and perceptions of the adoption of agroecological practices; (4) Results related to the adoption of agroecological practices (profile of farmers who are potential adopters of agroecological practices in the future).

The results related to the interview are divided into: agroecological practices already adopted, barriers to the adoption of agroecological practices and accelerators of the adoption of these practices. Regarding the already adopted agroecological practices, the most indicated practices were: Do not abuse the land; Try to maintain high soil conservation in terms of low tillage and promoting biodiversity by leaving vegetation cover; Do not pretend to substitute ones' inputs for others but then decrease them; Seek the balance between plant-soil-adventitious herbs; Change agricultural practices to improve the health of cultivated plant species. The most cited barriers to the adoption of agroecological practices were: the lack of advice and technical support for the conversion to agroecology; the lack of agroecological training for farmers; the lack of knowledge on the application of biopesticides; the lack of research on new phytosanitary products; the lack of citizen awareness; and, Difficulty in the control of MH without herbicides, among others. Regarding the accelerators, the most cited are: the possibility of introducing technological innovation in organic production methods; Payment for the product at a fair price; Farmers' ecological groups to support each other and facilitate the transfer of knowledge of agroecological practices; Maintaining or increasing the viability of crops; Obtaining support and social recognition for the farmer's ecological work; Offering quality; Experimentation on their own farm with effective and more respectful methods with the environment; Gratification of success, etc. The results related to the survey are subdivided into:

\subsection{Characteristics of Farmers and Their Farms}

In Figure 1 it can be seen that $30 \%$ and $27 \%$ of respondents belong to the horticultural sector and extensive crops (cereal, hops, etc.), respectively. Furthermore, $27 \%$ of the farmers have exploitations of 3 to 5 ha, while $20 \%$ cultivate exploitations of 6 to 10 ha. Some $43 \%$ 
of farmers cultivate family exploitation, while $28 \%$ rent their exploitations. The surveyed farmers ranged between 41 to 60 years of age.

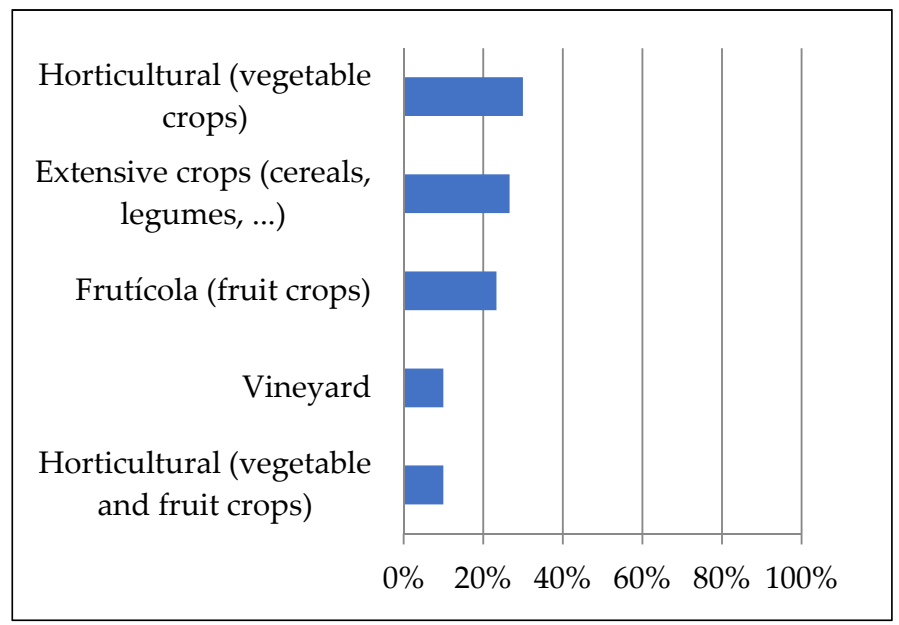

(a) Agricultural sector (surveyed)

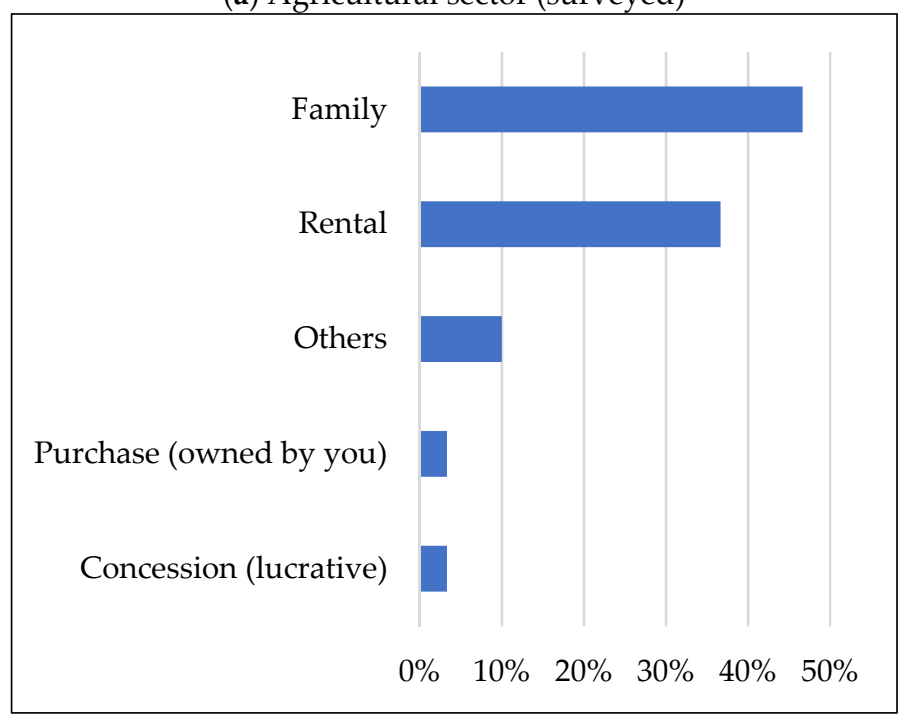

(c) Type of exploitation (\% surveyed)

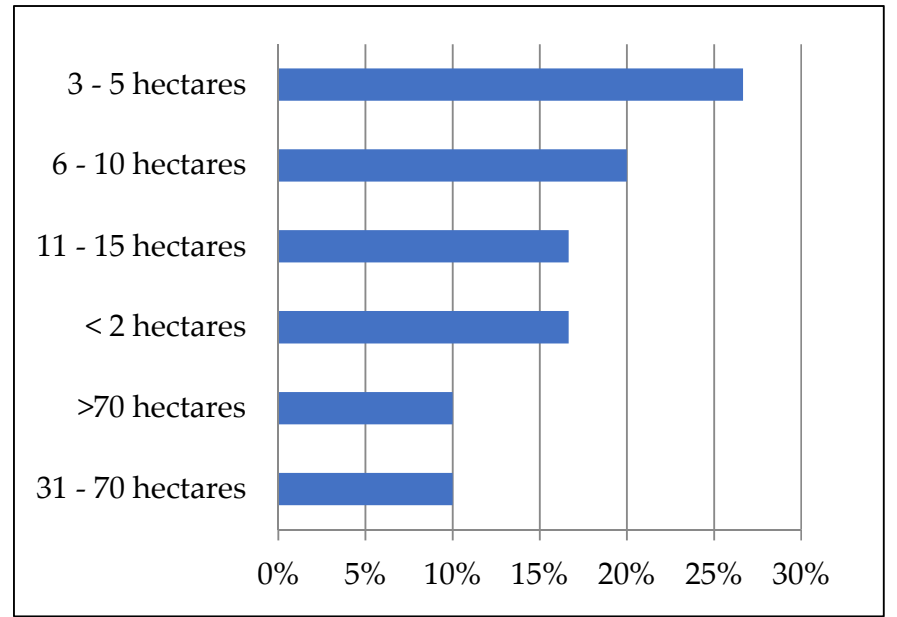

(b) Number of hectares (\% surveyed)

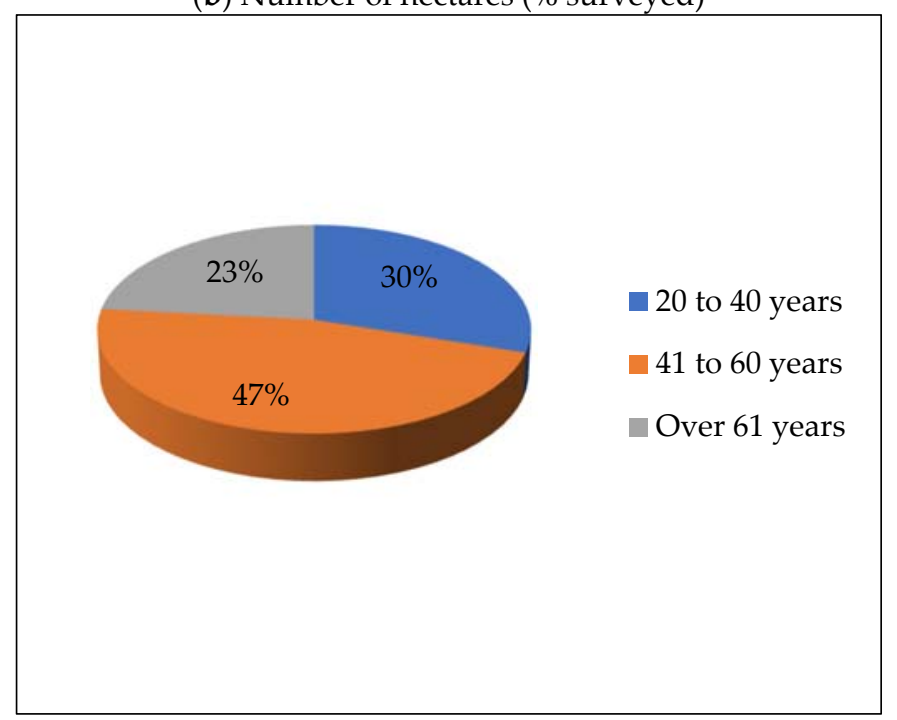

(d) Percentage of farmers according to age

Figure 1. Farmers and exploitation's characteristics.

\subsection{Level of Knowledge, Perceptions and Attitudes of Farmers towards Pesticides and Agroecological Practices}

Farmers understood by agroecological practices those agricultural practices which are ecological and meet the daily demands of exploitation while enhancing the natural processes of crops' defense. They are environmentally friendly practices which maximize ecosystem services. It is also a symbiosis between profitability and sustainability. Agroecological practices are those that allow food to be produced without using pesticides from chemical synthesis, neither herbicides nor transgenics, maintaining the regenerative capacity of the soil (its fertility) and the ecosystem's biodiversity. Producing agroecologically is producing with care and respect, living together in harmony with the environment and its natural surroundings. On the other hand, the farmers most reluctant to change practices commented that using agroecological practices is simply going from having a conventional farm to an ecological one with agricultural practices following the regulations of the CCPAE, or even that it is a scam since producing this way would require more time and inputs to have pathogen-free plants. Furthermore, for those who do ornamental farming it is very difficult for them to carry out agroecological practices. 
The level of knowledge that the farmers had about the aspects of agroecological practices, shown in Figure 2 were valued using a scale that goes from 1 (not informed) to 7 (very informed). The results show that farmers had a good level of knowledge about all aspects of agroecological practices. The aspects best known by farmers were the "cost of adopting agroecological practices", "Crop rotation", "crop diversification" and the general concept of "agroecological practices". The aspect that received the lowest valuation was "the production of agro-ecological products". Therefore, farmers need more information about the agroecological production system.

Cost of adopting agroecological practices

Crop rotation

Crop diversification

Agroecological practices

Price agroecological products

Quality agroecological products

Market (demand) agroecological products

Performance agroecological products

Use of phytosanitary products made from org. alive

Production agroecological products

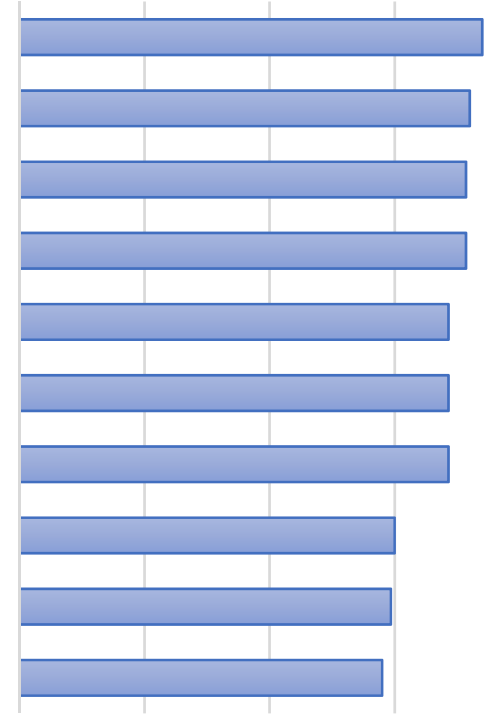

$\begin{array}{llllll}1 & 2 & 3 & 4 & 5 & 6\end{array}$

7

Figure 2. Scaled average according to the degree of knowledge about different aspects of agroecology.

$53 \%$ of farmers had very little information on agrochemicals, $57 \%$ of farmers had very little information on the negative health effects of agrochemicals and, as Figure 3 shows, $83 \%$ of farmers affirmed that agrochemicals are a health risk.

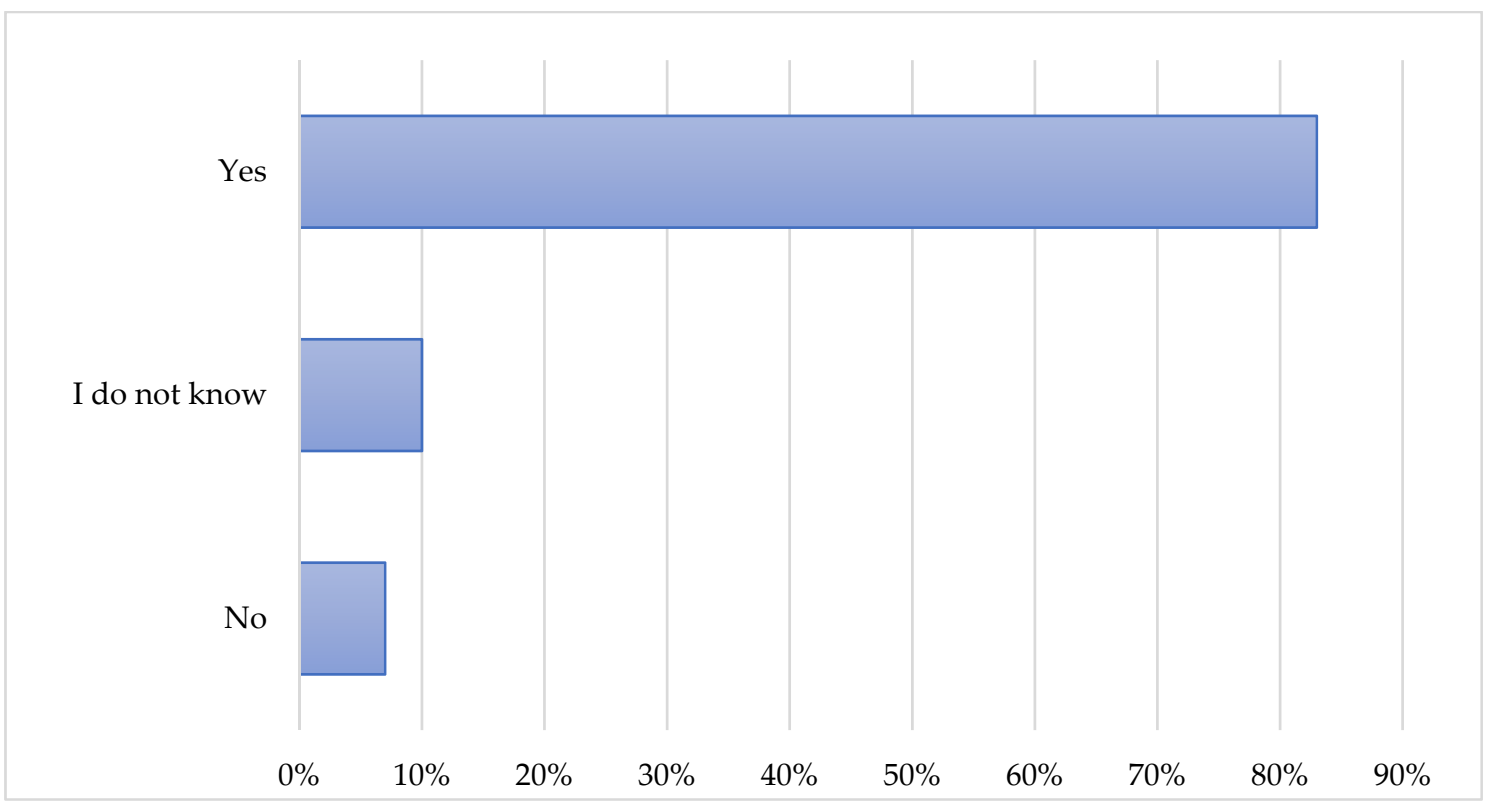

Figure 3. Percentage of farmers who affirm or deny that agrochemicals are a health risk. 
In Figure 4 we can see how the media that offer farmers more information about the agrochemicals and their possible negative consequences on health are: 'agrochemical labels' with $28 \%$ of the respondents, 'Internet' with $25 \%$ and participation in 'Courses' with $17 \%$.

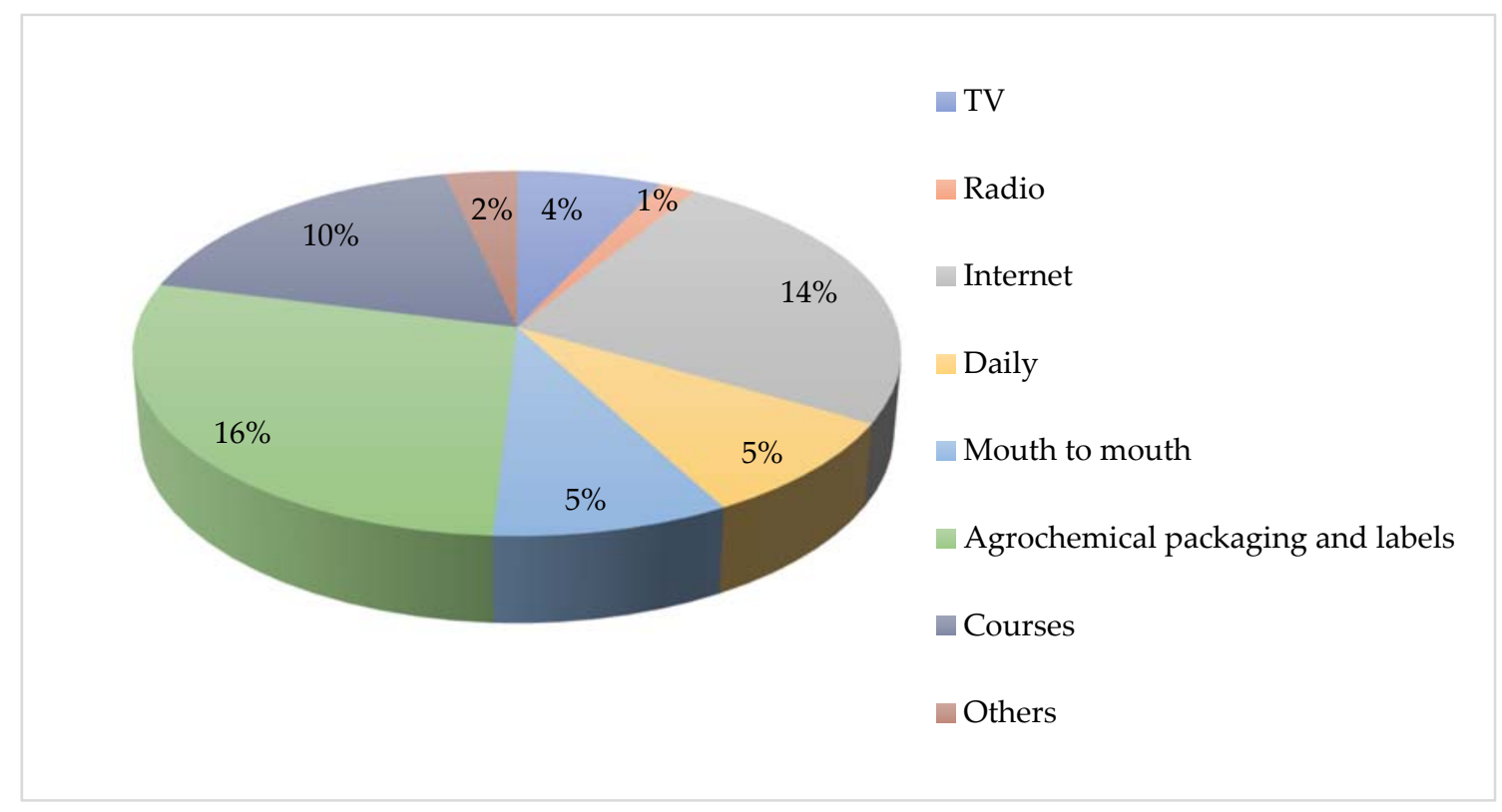

Figure 4. Percentage of farmers according to the communication medium observed.

\subsection{Main Brakes, Accelerators and Perceptions in the Adoption of Agroecological Practices}

In Figure 5 it can be seen that the most important brakes/barriers for farmers when it comes to adopting agroecological practices are: "Loss of producer income", "Lack of social awareness regarding the production of ecological products", "Low prices at origin and/or market", and "lack of agroecological training, technical and research advice". On the other hand, we have the less important barriers such as "low diversity organic products", "the economic situation does not allow to put agroecology into practice", and the "type of soil and relief of the farm". Thus, farmers tend to give more importance to those barriers that are more focused on the economic field (related to aid and payment for product), social (the ecological product or the production of organic products is not fully assimilated by the consumer), academic (lack of knowledge on the norms and use of ecological pesticides and advice by technicians) than those of an agronomic type (typology and soil relief, new varieties adapted to the conditions of the area, yields, etc.).

In reference to accelerators when adopting agroecological practices the most notable for the farmers were: to "Know experiences of other farmers", the "Rigor of legislation and product ecological standards" and a "favorable cultural environment to motivate the adoption of agroecological practices". Receiving the lowest rating was "Government Support (Grants)". Therefore, farmers demanded more rigorous exterior and interior policies in which the adoption of agroecological practices are favored. In addition, knowing the experiences of other farmers who practice organic farming is of vital importance since amongst themselves they understand each other much better than, for example, the administrators. Thus, exchanging experiences between groups of farmers in a specific area would facilitate the transfer of knowledge in agroecological matters, thus facilitating the adoption of these practices (Figure 6). 
Producer loss of income

Lack of social awareness regarding the production of eco products

Low prices at origin and / or market

Lack of agroecological training in farmers

Lack of technical advice and support

The type of demand and the willingness to pay of consumers

Receive a low price for a high demand for organic products

Reduction of aid from the Common Agricultural Policy

Lack of research

Low levels of education and training in pesticide handling

Limited knowledge of pesticide use regulations

Unfair competition from other producers

High perception of the efficacy of chemical pesticides

Low efficiency of organic products

Low yields of agroecological practices

Contamination of the plot by third parties

Lack of knowledge when applying biopesticides

Climatology

Low diversity of organic products

The economic situation (income) does not allow it

The irregular relief of the farm

The type of soil

Depending on the type of soil, there are viable agroecological practices (or not)

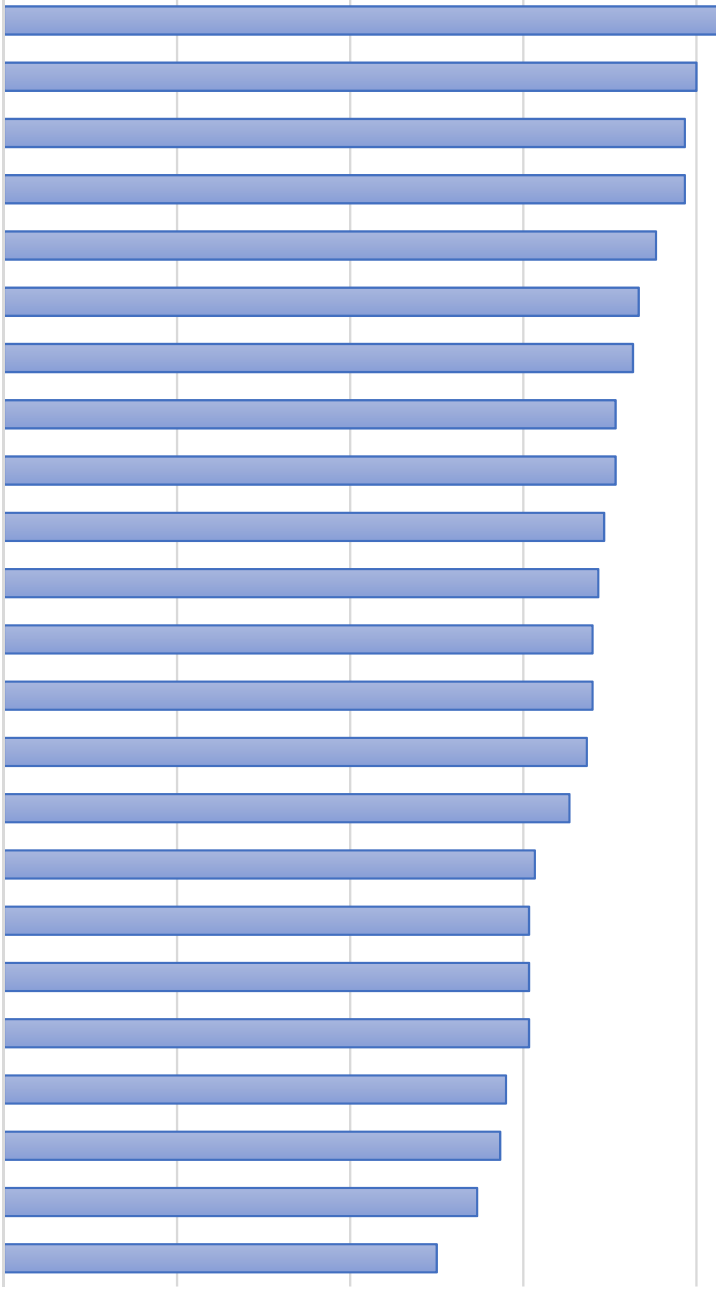

1.00

2.00

3.00

4.00

5.00

Figure 5. Average according to the different barriers when adopting (or not) agroecological practices. 


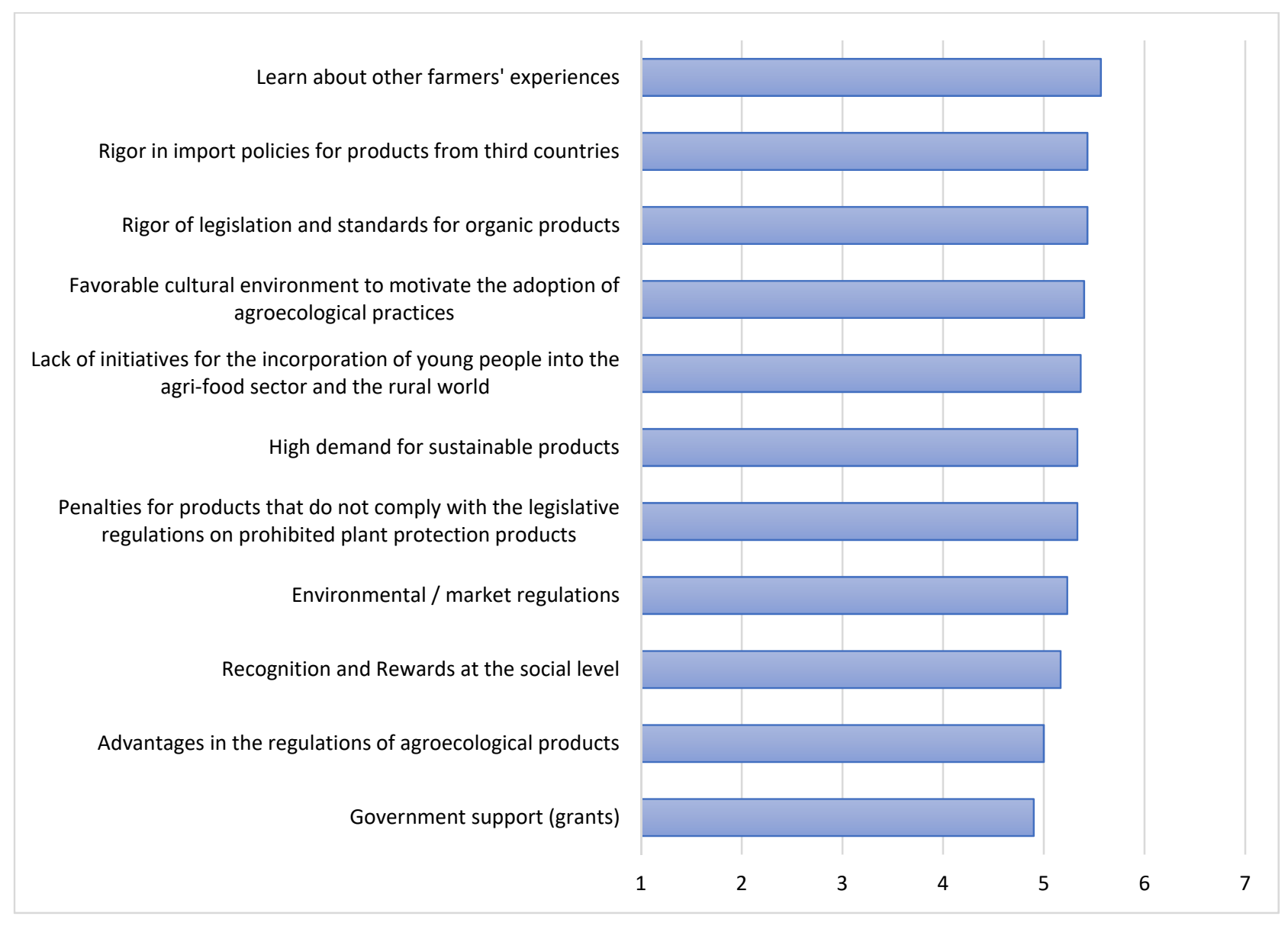

Figure 6. Scalar average according to the degree of importance of a series of factors on adoption of agroecological practices.

The benefits most perceived by farmers are "Agroecology reinforces the health and well-being of the soil, environment, producer and consumer", "Agroecology allows to protect and/or conserve ecosystems", "Agroecology reduces environmental deterioration" and "Agroecology incorporates ancestral values and knowledge of an avant-garde character". The aspects that received the lowest valuation were "Agroecology increases sovereignty of the farmer", "Agroecology allows the generation of medium-high benefits", "Agroecology eliminates hunger, poverty and negative consequences for the environment", "Government support" and "Agroecology empowers the farmer set the final price of the product". Therefore, farmers were clear that agroecology is not only based on the production of food without the use of synthetic chemical pesticides, but rather puts includes the value the ecosystem of the farm, that of its surroundings and that of the planet, thus contributing to the reduction of pollution and environmental deterioration. Besides, agroecology can be one of the agricultures of the future, with great weight in the development and research of new phytosanitary products of animal or natural origin for the control of pests and diseases. On the other hand, they did not see clearly that agroecology will allow them to have sovereignty over their products and ways of doing agriculture, or that it will be a practice that contributes to eradicating hunger in the world (Figure 7). 
Agroecology makes it possible to reduce the use of pesticides and synthetic chemical fertilizers Agroecology reinforces the health and well-being of the soil, the environment, the producer and the consumer

Agroecology makes it possible to protect and / or conserve natural ecosystems

Agroecology reduces environmental degradation

Agroecology incorporates ancestral and avant-garde values and knowledge

Agroecology increases R\&D for more efficient organic products

Agroecology reduces the use of fossil fuels

Agroecology increases farmer participation and decision-making at the individual and community levels

Agroecology makes efficient use of natural resources

Agroecology constitutes equitable and sustainable production, distribution and consumption networks

Agroecology promotes the proximity sale of its product / s

Agroecology Aims to change the sociocultural model towards a more sustainable one

Agroecology promotes the circular economy

Agroecology increases favorable conditions in contracts with clients

Agroecology reduces excessive food consumption

Agroecology allows for an equitable distribution of agroecological products Agroecology values collaboration to promote the change of the current agri-food system to a more sustainable one. This is due to the support of producers, marketers, companies, consumers, ...

Agroecology supports and collaborates with other farmers

Agroecology increases farmer sovereignty

Agroecology allows generating medium-high benefits

Agroecology eliminates hunger, poverty and negative consequences for the environment

Government support

Agroecology gives the farmer the power to set the final price of the product
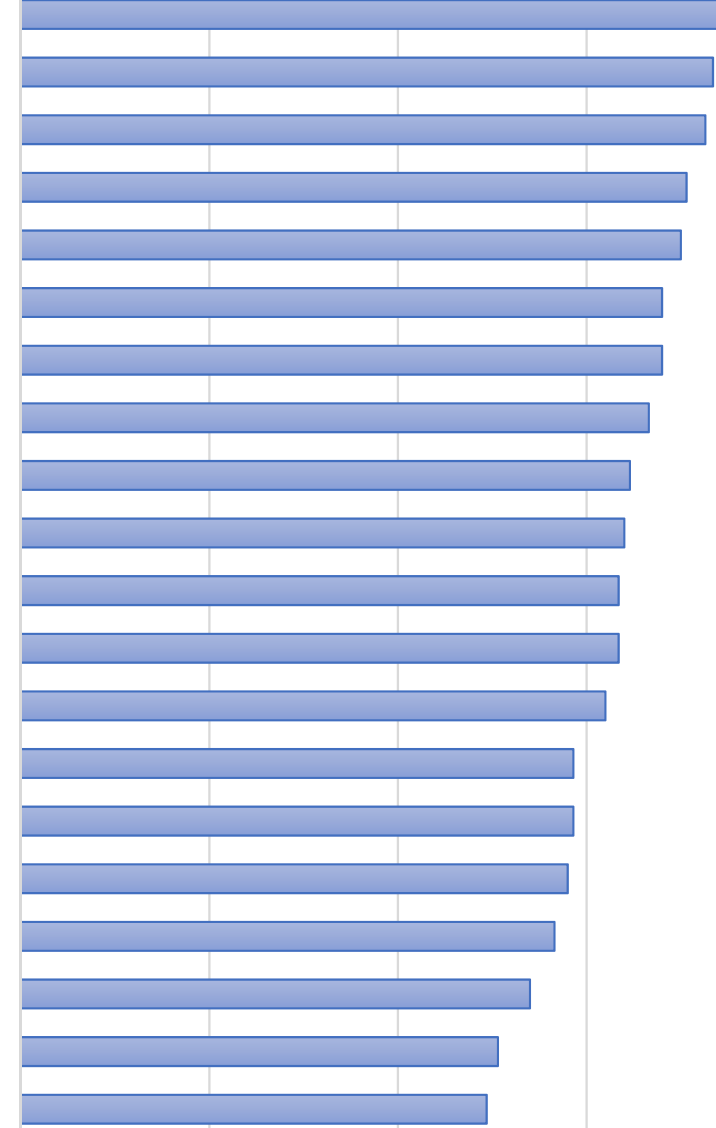

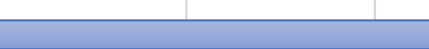
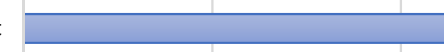

1

Figure 7. Scalar average according to the assessment of some statements related to agroecological practices. 


\subsection{Results Related to the Adoption of Agroecological Practices}

The agroecological practices most adopted by farmers so far are "Organic fertilization", the "Reduction of the use of inputs harmful to the environment", "Conservation agriculture", "Biological control of pests", "Drip irrigation", "Split fertilization" and "Choice of crops and rotations". This is shown in Table 2.

Table 2. Number of farmers who have chosen each practice and number of practices who have chosen each of the farmers.

\begin{tabular}{lc}
\hline \multicolumn{1}{c}{ Practices } & Number of Practices \\
\hline Organic fertilization & 19 \\
Reduction in the use of inputs that are harmful to the environment & 19 \\
Conservation agriculture (soil protection through soil cover with plant remains from a & 18 \\
previous crop, planting of plant covers, etc.) & 18 \\
Biological pest control & 17 \\
Drip Irrigation of Crops & 16 \\
Split fertilization & 14 \\
Choice of crops and rotations & 13 \\
Biofertilizer & 13 \\
Use of the soil's own organisms to promote the activity biological soil to increase crop yields & 11 \\
and promote soil health & 11 \\
Create plant barriers around your crops, plots or the same farm & 12 \\
Polyculture; Diversification of cultivable species on the same farm & 11 \\
Production of organic fertilizers & 10 \\
Elimination of synthetic chemical pesticides & \\
Choice of cultivars & \\
\hline
\end{tabular}

With respect to the intention to adopt agroecological practices in the future, with an average adoption of $5.07,40 \%$ show a high probability of adoption. In the short term, the most adopted practices will be: "Reduction of the use of inputs harmful to the environment", "Drip irrigation of crops", "Effective management of nutrients and biomass", and "Conservation Agriculture". In the medium term they will be the "Elimination of synthetic chemical pesticides", the "Choice of crops and rotations", the "Reduction of the use of inputs harmful to the environment" and "Tillage 0 "; and, in the long term, the "Use of the soil's own organisms", the "Use of crops resistant to any stress", the "Use clean and efficient technologies", among others and will never be: "Agroforestry", "Tillage 0", "Divided fertilization", etc.

\subsection{Profile of Potential Farmers Adopting Agroecological Practices in the Future}

At this point, the variable "Intention to adopt agroecological practices in the future" was measured on a scale from 1 to 7 , with the characteristics of the farmers and their farms. The graphs shown below were where the variable "intention to adopt" was statistically higher. Therefore, those farmers who had a higher intention to adopt agroecological practices in the future are those who engage in other types of sectors, that is, fruit and vegetable crops, extensive crops and vineyards as compared to horticultural and fruit crops (Figure 8), those who practice conventional and integrated agriculture compared to organic (Figure 9), those with a cultivable area of 11ha compared to those who have fewer ha (Figure 10), those who have more experience in the adoption of agroecological practices compared to those who have the least (Figure 11), those who have a lot of confidence in the different sources of information exposed in the questionnaire (Government, Producers, Associations or cooperatives of producers, Universities, Media (Newspapers, TV, radio), Neighboring producers or friends, Family, friends, colleagues, Social networks (Twitter, Facebook, etc.), and the EU) (Figure 12), those who have a lot of information with regard to agrochemicals compared to those who have little (Figure 13), and those who have a high concern for the health effects of agrochemicals (Figure 14). 


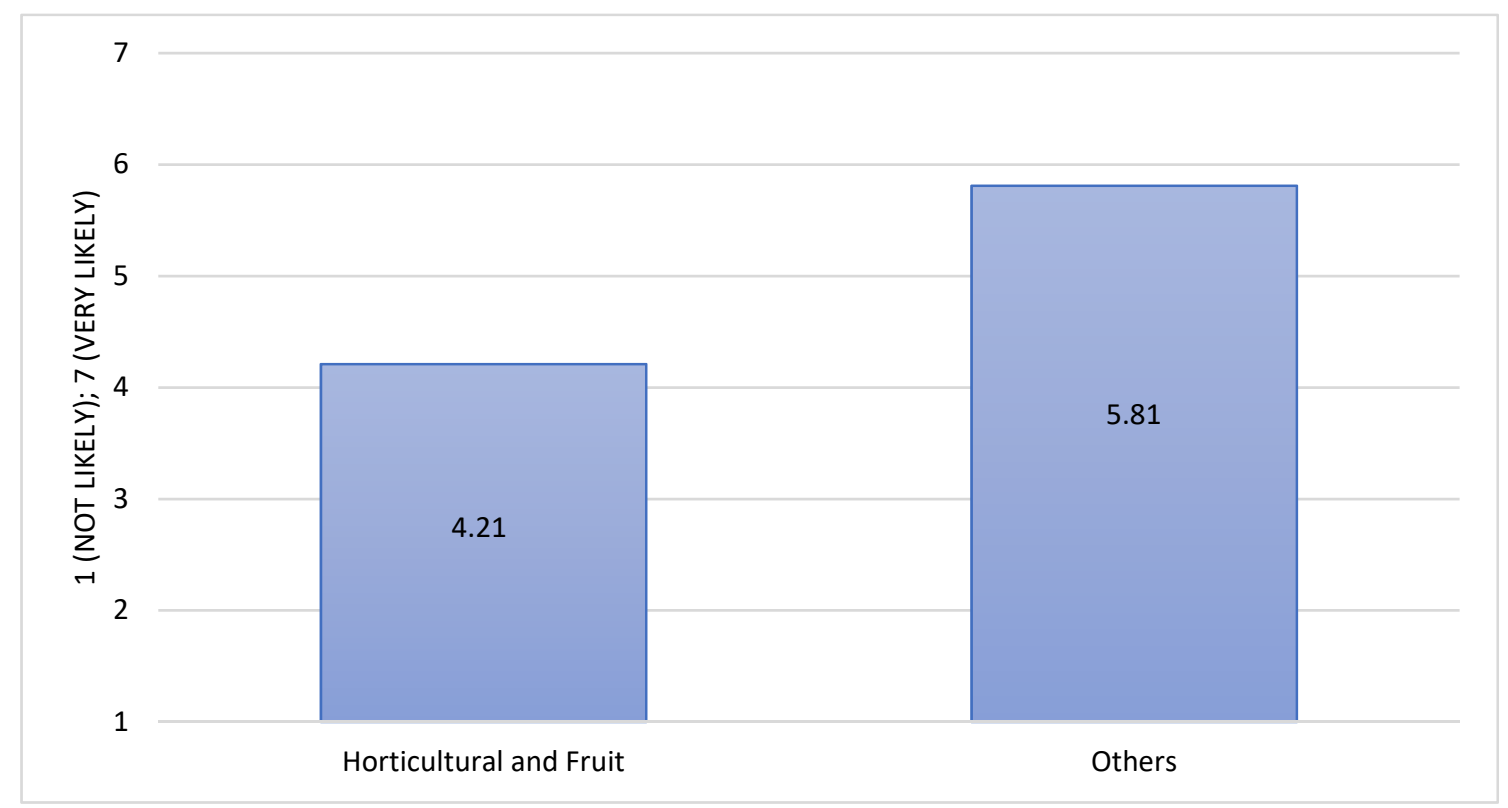

Figure 8. Probability of adopting agroecological practices depending on the sector that the farmers belong to.

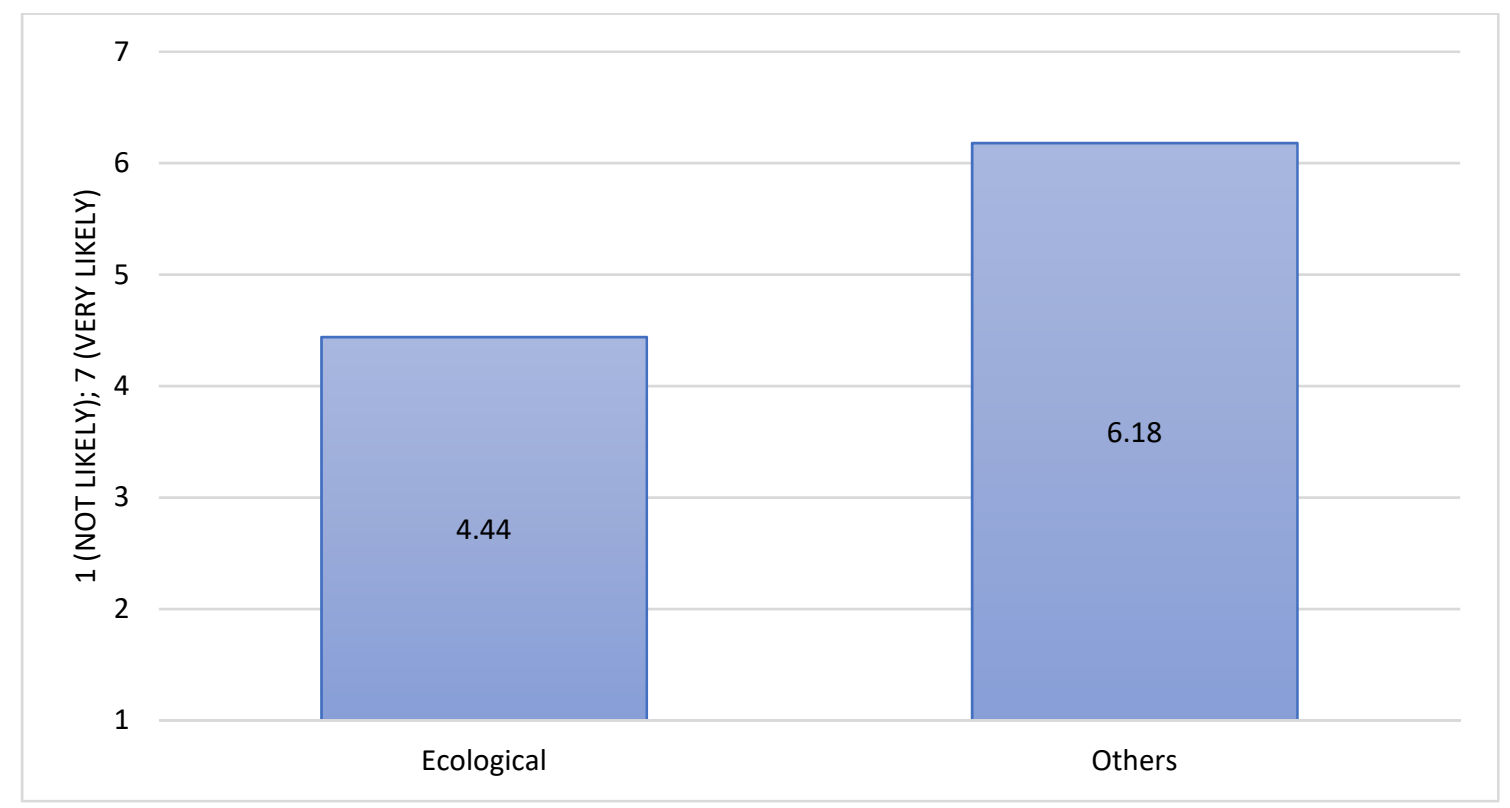

Figure 9. Probability of adopting agroecological practices in the future depending on the type of agriculture practiced by the farmers. 


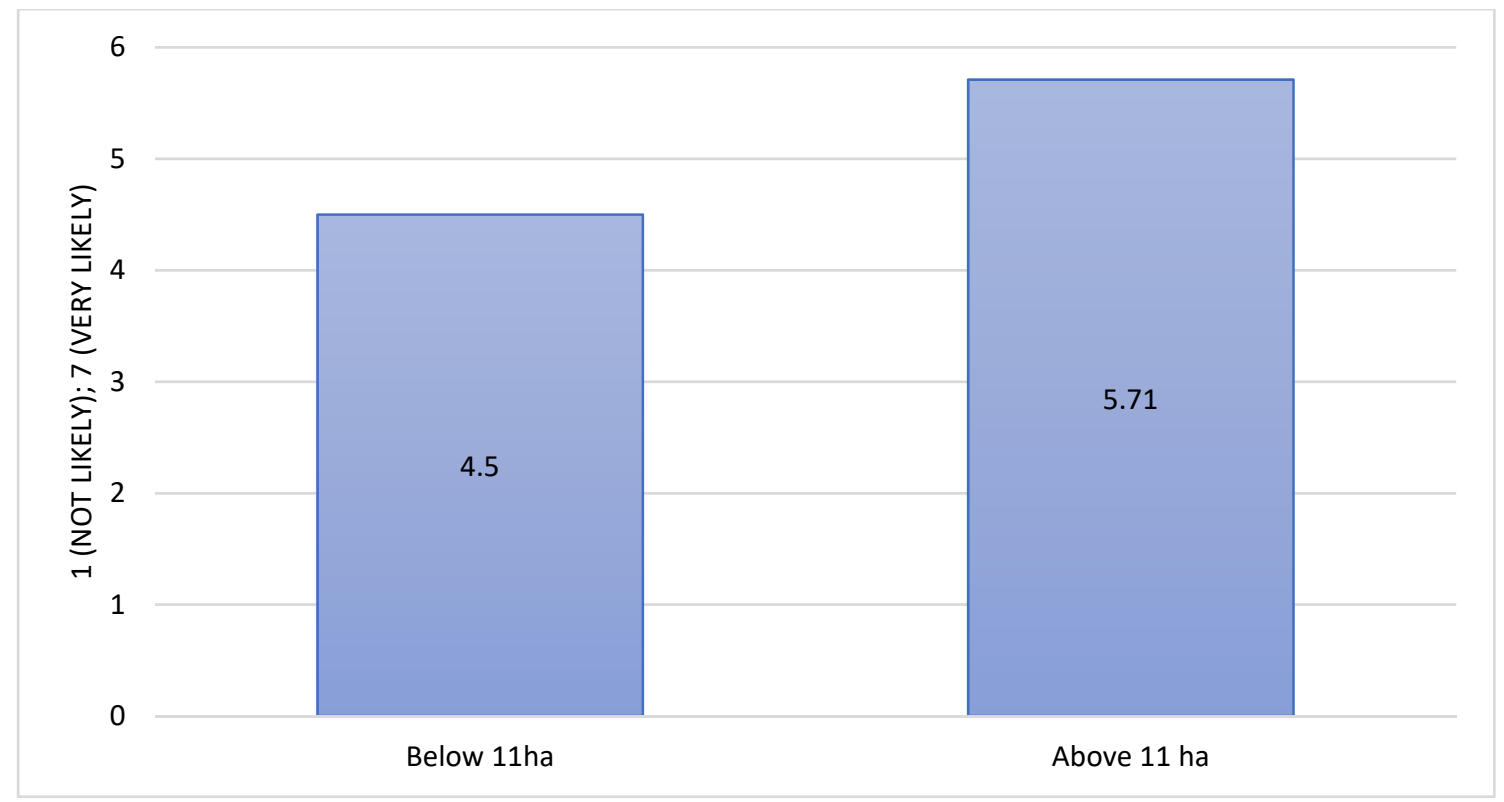

Figure 10. Probability of adopting agroecological practices in the future depending on the size of the farm.

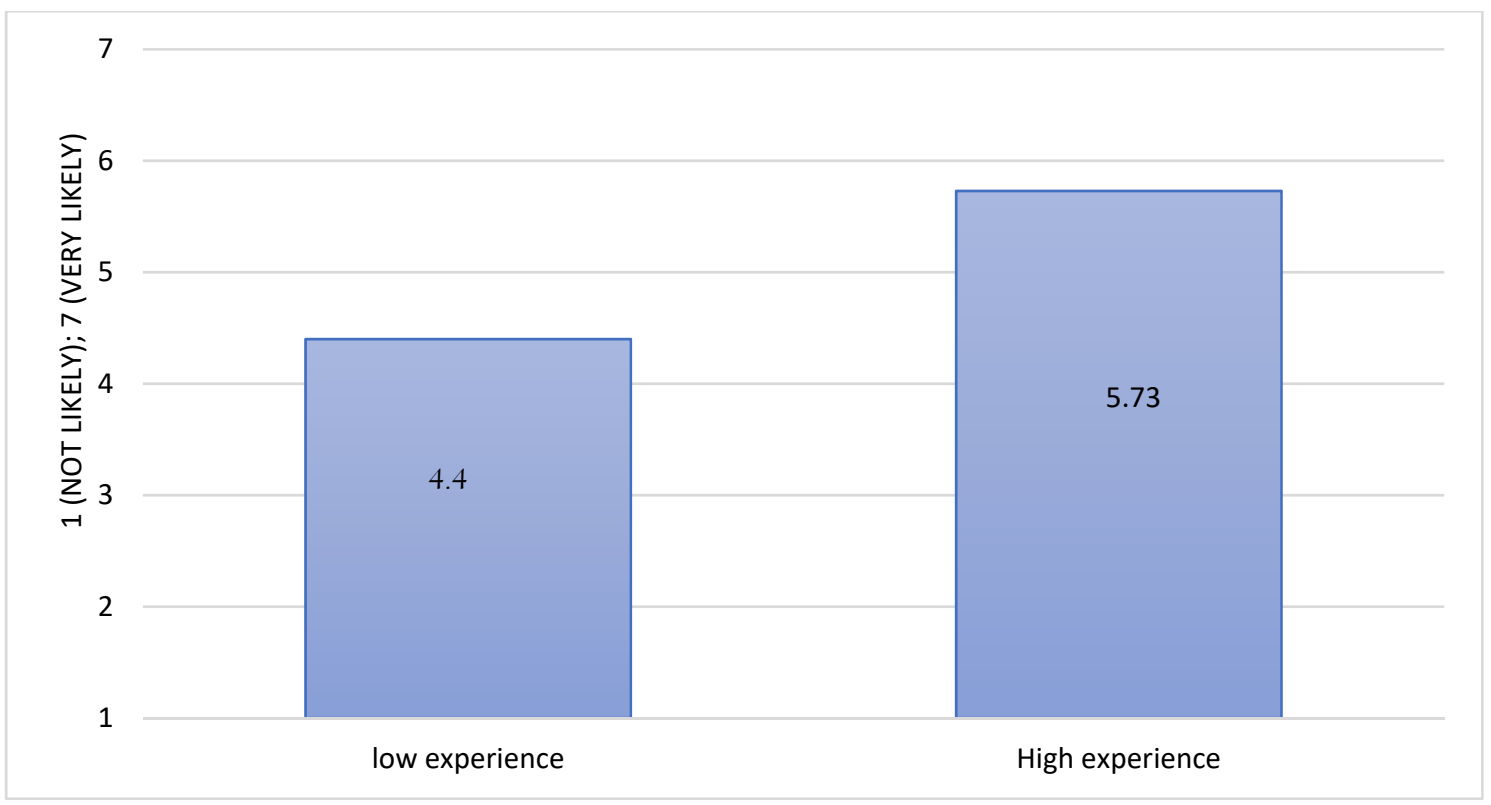

Figure 11. Probability of adopting agroecological practices in the future based on farmers' experience with agroecological practices. 


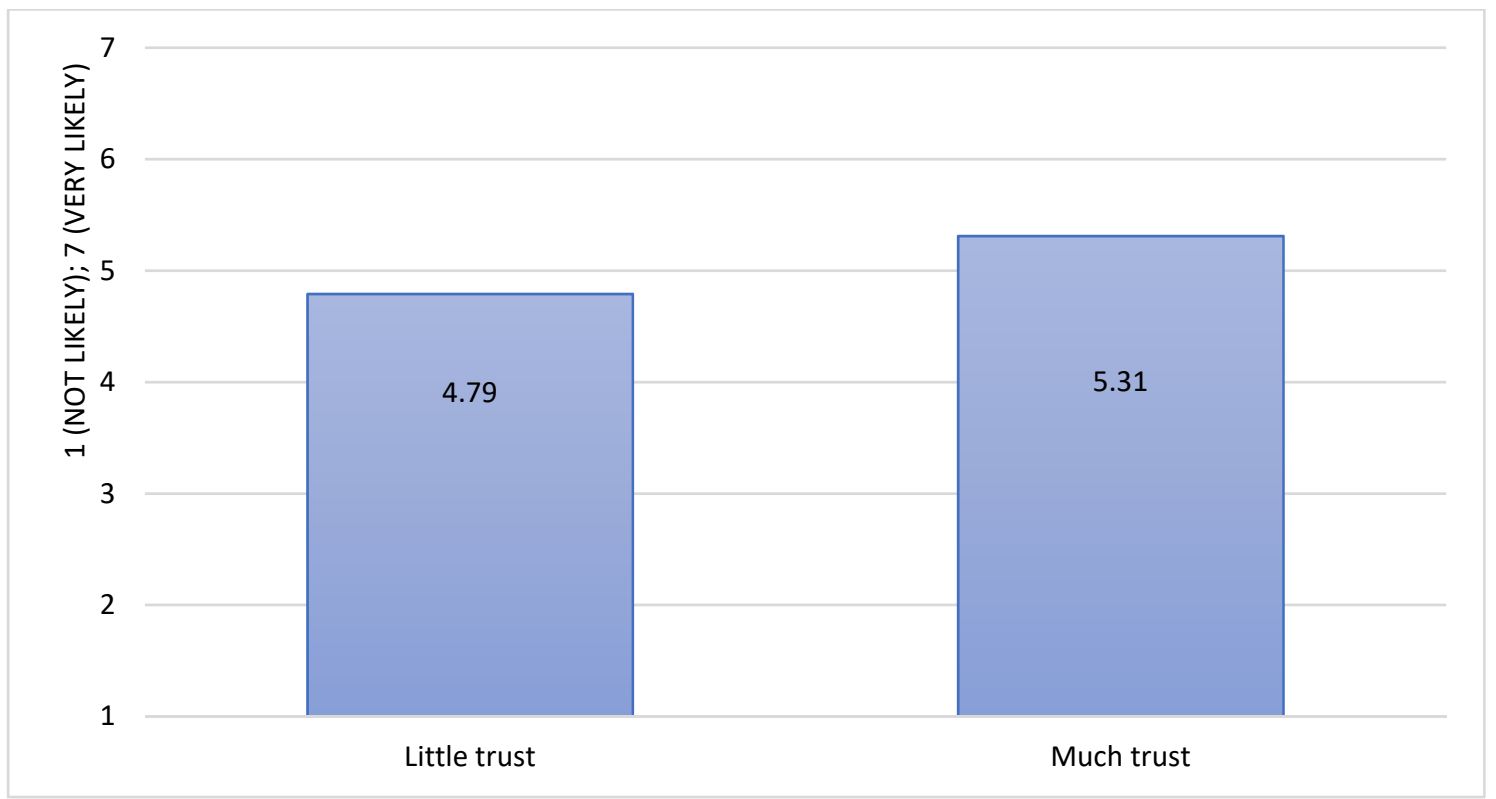

Figure 12. Probability of adopting agroecological practices in the future based on trust in information sources related to the adoption of agroecological practices.

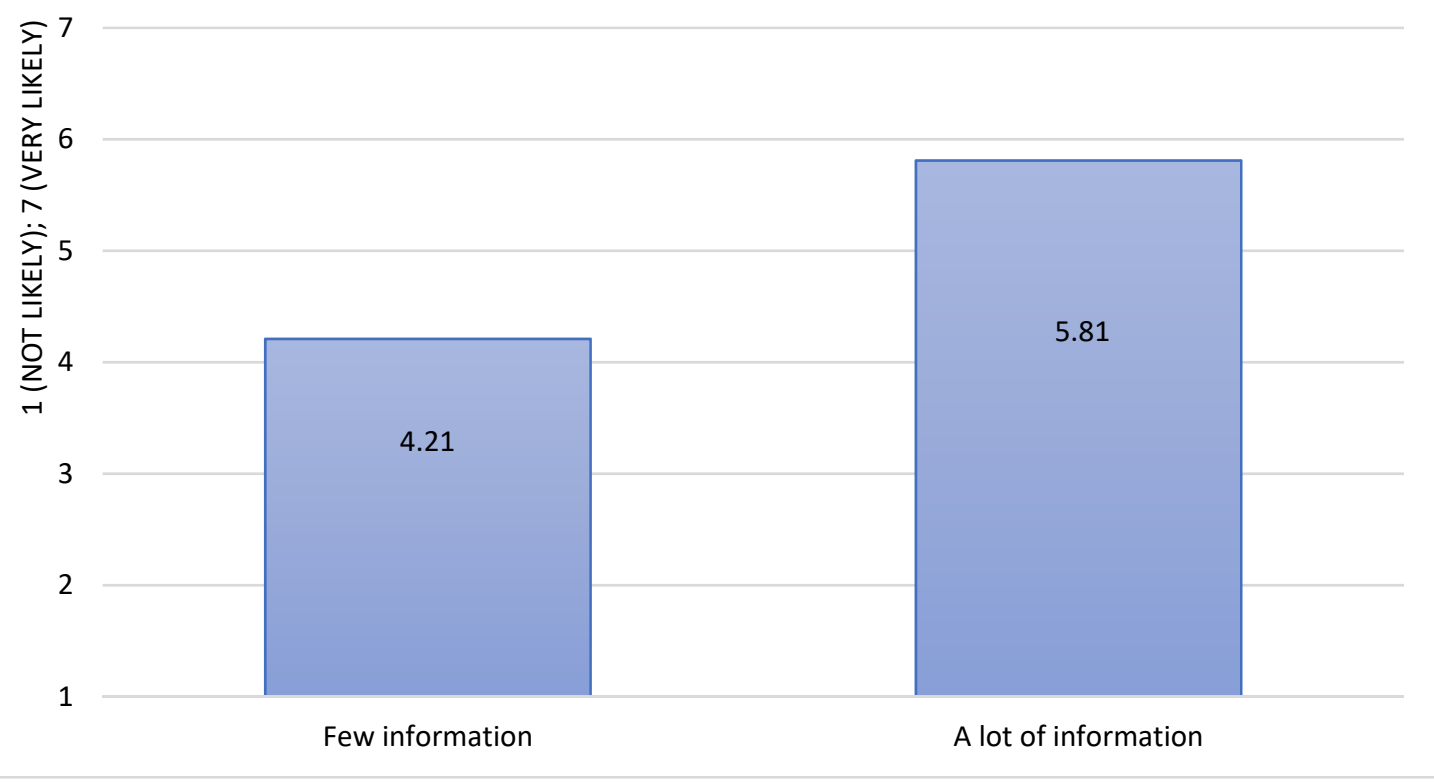

Figure 13. Probability of adopting agroecological practices in the future depending on the degree of information regarding the agrochemicals. 


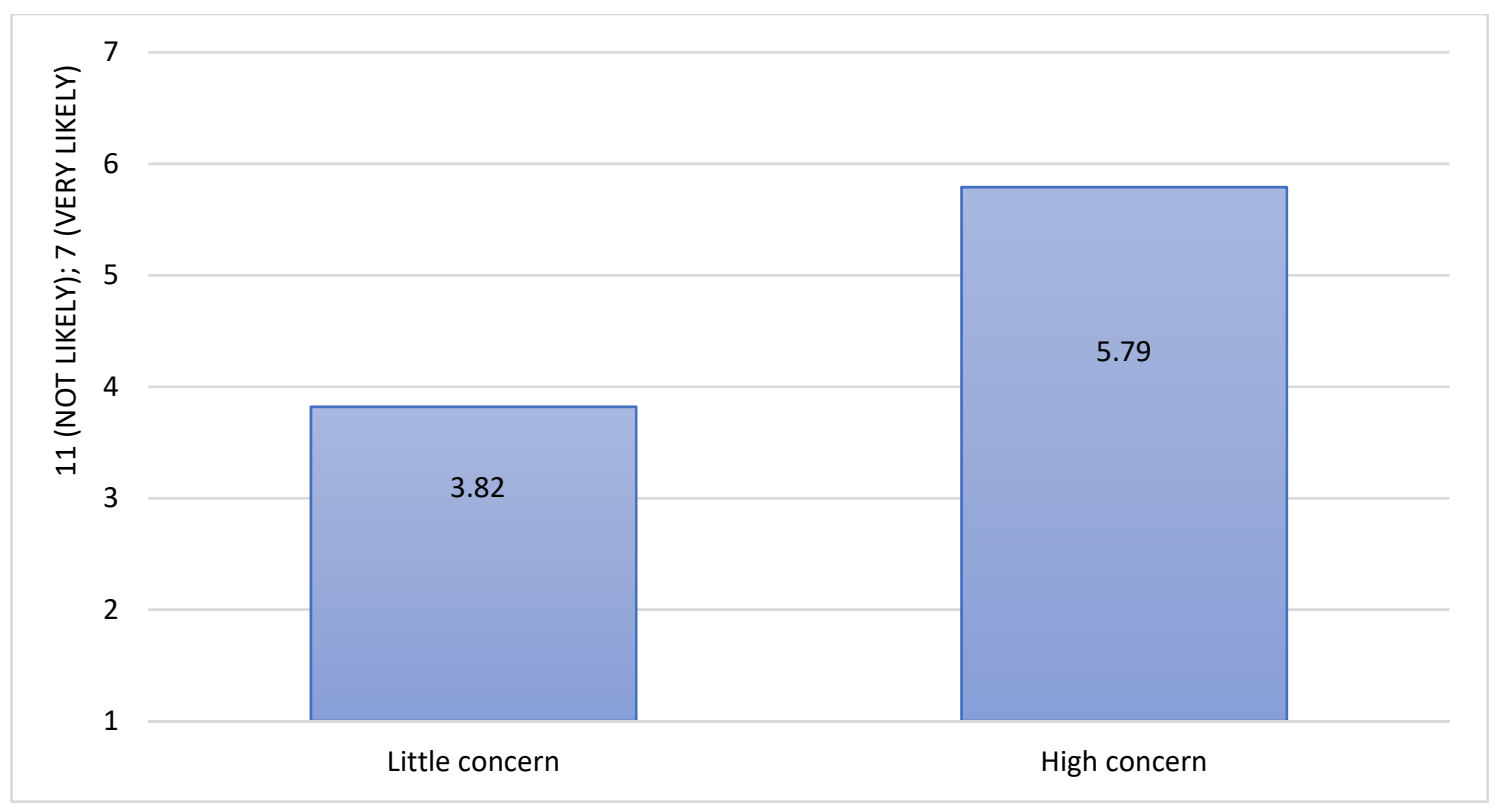

Figure 14. Probability of adopting agroecological practices in the future depending on degree of concern for the effects of agrochemicals.

\section{Discussion}

The results show that the main obstacles to the adoption of agroecological practices are focused on the economic sphere and are related to subsidies and low prices received for product at origin, coinciding with the results of other studies $[11,14,19]$. Other obstacles include social (organic products not fully assimilated by consumers), political (lack of attention on the part of institutions, as in [20]), academic (lack of knowledge of the norms around the use of ecological pesticides and access to advice by technicians that is essential to avoiding problems at the time of adoption [11,15,23]), and agronomic (typology and soil relief, new crop varieties not adapted to the conditions of the area, low yields of organic farming); all of these coincide with the results of other studies [14,20,24]. On the other hand, farmers do not see clearly that agroecology can allow them to have sovereignty over their products and ways of doing agriculture, or that its contribution is key to the eradication of hunger in the world. Horrillo et al. [12] showed that the production cost of ecological farms is high and highlighted the need for ecological farms to be compensated with subsidies for their contribution to territorial and biodiversity conservation and the provision of ecosystem services. Horrillo et al. [13] also reported that ecological livestock production is a sustainable model which benefits society by providing several ecosystem services, including carbon sequestration. They suggested that the imposition of a tax on $\mathrm{CO}_{2}$ emissions will benefits ecological farms, improving their incomes.

Potential accelerators of the adoption of agroecological practices identified by farmers include the demand for more rigorous foreign and domestic policies in which they favor the adoption of such practices as good planning and policy management [14], and for the opportunity to learn about the experiences of other farmers who practice organic farming in specialized centers for the transfer of knowledge in agroecological matters. This, compared to the transfer of knowledge through public and/or private institutions, would guarantee greater successful adoption of agroecological practices due to the simple fact that there is greater trust among farmers. The lack of knowledge transfer is linked to the lack of stimulation to learn new agricultural practices $[11,15,20]$.

The most adopted agroecological practices by farmers are: organic fertilization (reducing the use of inputs harmful to the environment), conservation agriculture, biological pest control, drip irrigation, divided fertilization (fertilization according to the demands of the crop and the growing period), choice of crops resistant to biotic and abiotic actions of 
the environment, and crop rotation. Other techniques adopted are cultivating according to the calendar and cycle moles, practicing solarization (a physical strategy to control soil pathogens), use of plastics to avoid water losses and reduce the use of herbicides, use of long-life boxes in the handling and sale of products, and the use of farm birds to combat pathogenic insects.

On a scale from 1 (Not at all likely) to 7 (Very likely), the intention to adopt agroecological practices in the future stands at an average of 5.07 points. Regarding the above, $60 \%$ of the farmers indicated a below average intention to adopt, which indicates that more than half are not considering adopting. However, the intentionality of adoption deepened for the choice of agroecological practices in the short, medium and long term. Therefore, the agroecological measures most adopted in the short term have been the reduction of the use of inputs that are harmful to the environment, drip irrigation of crops, effective nutrient and biomass management, and conservation agriculture; in the medium term, the elimination of synthetic chemical pesticides, the choice of resistant crops and rotations of crops, reducing the use of inputs harmful to the environment, and tillage 0 ; and, in the long term, taking advantage of the soil's own organisms, the use of stress-resistant crops, the use of clean and efficient technologies, and not depending $100 \%$ on external inputs from the farm.

Farmers, in general, have little confidence in the main sources of information on agroecological practices. The most prominent sources on the part of the farmers are "Family, friends, colleagues", other "producers" and "University".

The surveyed farmers who are dedicated to extensive crops, fruit and vegetables and integrated production have an intention to adopt agroecological practices in the future greater than those dedicated to horticulture and fruit culture. The same happens with conventional farmers and integrated production compared to ecological production; those with more than 11 arable hectares of land compared to those with less than 11 hectares; those who have already adopted more agroecological practices compared to those who have not; those who most trust the different sources of information on agroecological practices compared to those who least trust these sources of information; furthermore, farmers who feel highly informed about agrochemicals are more likely to adopt agroecological practices in the future (contrary to [9]), as are those very concerned about the negative effects of agrochemicals on the health compared to less concerned farmers.

The potential farmer adopting agroecological practices in the future can be described as: a farmer who is dedicated to the cultivation of cereals, fruits and vegetables and a practitioner of integrated production, with a background in conventional or integrated agriculture, who has more than 11 cultivable hectares, relies on different sources of information related to agroecology, has high experience with agroecological practices, and feels very informed about agrochemicals and very concerned about the negative effects they may have on both the health of the population and the environment. Parra López and Calatrava Requena [25] reported that compared to conventional growers, organic growers are younger, with a part-time dedication to agriculture, with less productive orchards, more involved in management and administration of the holding and more informed about organic agriculture. Läpple and Van Rensburg [26] showed that early adopters were the youngest to adopt organic farming. Djokoto et al. [27] found that being male, being from a smaller household and having access to credit was correlated with a tendency towards adopting organic cocoa production. According to Ashari et al. [28], the information and knowledge, economic and financial resources, technical and management skills, social aspects, environmental concern, institutional environment, and socio-economic and demographic characteristics of farmers are the key factors of organic farming adoption. Lohr and Salomonson [29] and Pietola and Lansink [30] demonstrated the role of subsidies in encouraging farmers to adopt organic conversion. 


\section{Conclusions}

In general, farmers need to be provided with more information about the agroecological production system through means closer to them such as friends, other producers in the same sector, university trials in experimental fields and that these belong to an organic producer because this way it will serve as an example to gain a certain positive perspective for adopting agroecological practices.

On the other hand, there is no significant difference in the intention to adopt agroecological practices in the future among the farmers who have been working in the agricultural sector for more than 20 years and those who have been working in the agricultural sector for less than 20 years, among the farmers who have family or rental farms and those who have concession and/or purchase farms, among those who have indicated a greater number of barriers to the adoption of agroecological practices and those that have indicated a lower number of barriers, among farmers who perceive many benefits of adopting agroecological practices in the future and those who do not perceive or perceive few benefits, among risk-disliking farmers and risk-takers, among highly productive farmers environment and those who are not so protective of the environment, among farmers whose age is higher than the average age of the sample (48 years) and farmers whose age is lower than the mean age of the sample, and there is no difference in the intention to adopt agroecological practices in the future among men and women; nor among those who say that agriculture is or is not the only source of income their household receives. There is also no significant difference in the intention to adopt agroecological practices among those with university and secondary education and those with primary or simple studies.

With all the data collection, the profile of the potential farmer adopting agroecological practices in the future can be described as: farmer who dedicates to the cultivation of cereals, fruits and vegetables and a practitioner of integrated production, from conventional and integrated agriculture, who has more than 11 cultivable hectares, relies on different sources of information that provide information related to agroecology, with high experience with agroecological practices, feels very informed about agrochemicals and very concerned about the negative effects they may have on both the health of the population and the environment.

Producing in an ecological way implies higher production cost which forces farmers to sell the resulting product at higher prices than conventional ones. Consumers interest in organic products in increasing, however, the prices are a barrier. So, policymakers should support economically farmers paying them for the ecosystem services they provide to society. Our findings are in line with the theory. Farmers' knowledge and familiarity with the agroecological practices should be increase through informative campaigns; training and education. Farmers' access to technologies innovations should be guaranted. Consumers' awareness and knowledge should be also improved.

The present study is an exploratory study where a small sample size of farmers was used. This is the main limitation of this study. Future research should use the findings of the present study as a basis for more extended studies with a large and representative samples. Future research should also extend the research to more sectors. It will be interesting to estimate a model based on the Theory of Planned Behavior to better explain farmers intention to adopt agroecological practices.

Supplementary Materials: The following are available online at https://www.mdpi.com/article/10 .3390/agronomy11101959/s1, Survey S1 and Database S1.

Author Contributions: A.P.P.: Formal análisis, Investigation, Methodology, Visualization and Writing—original draft; D.R.: Project administration, Resources, Supervision, Validation and Writingreview \& editing; M.d.M.C.D.: Writing-original draft. All authors have read and agreed to the published version of the manuscript.

Funding: This research received no external funding. 
Institutional Review Board Statement: The study was conducted according to the guidelines of the Declaration of Helsinki, and approved by the Ethics Committee of Centro de Investigación en Economía y Desarrollo Agroalimentario.

Informed Consent Statement: Informed consent was obtained from all subjects involved in the study.

Data Availability Statement: Data are included as Supplementary Material.

Conflicts of Interest: The authors declare no conflict of interest.

\section{References}

1. Sarandón, S.; Flores, C. Agroecología: Bases Teóricas Para el Diseño y Manejo de Agroecosistemas Sustentables, 1st ed.; Universidad Nacional de La Plata: La Plata, Argentina, 2014.

2. Rica, U.D.C.; José, S.; Rica, C. Fundamentos culturales, sociales y económicos de la agroecología. Rev. Cienc. Soc. (Cr) 2014, 1, 93-102.

3. Wezel, A.; Casagrande, M.; Celette, F.; Vian, J.F.; Ferrer, A.; Peigné, J. Agroecological practices for sustainable agriculture. A review. Agron. Sustain. Dev. 2014, 34,1-20. [CrossRef]

4. Sánchez, M.; Sanjuán, A.I.; Gil Roig, J.M.; Gracia, A.; Soler, F. Estudio de las preferencia de consumidores y distribuidores especializados respecto del producto ecológico. Econ. Agrar. Recur. Nat. 2011, 2, 93. [CrossRef]

5. Mira, N.G. Estudio Sobre la Evolución de la Tipología y Perfil Sociodemográfico del Consumidor de Alimentos Ecológicos; Universitat Politècnica de València: València, Spain, 2018.

6. Munloz, P.F. Consumo Sostenible: La Brecha De La Alimentación Ecológica Entre Europa, Trabajo Fin De Grado; Universidad Pontificia de Salamanca: Salamanca, España, 2019; pp. 1-70.

7. Díaz, F.M.; Pleite, F.M.C.; Martínez-Paz, J.M.; García, P.G. La disposición a pagar por alimentos ecológicos en España: Una aproximación a la existencia de diferencias regionales1. ITEA Inf. Tec. Econ. Agrar. Rev. Asoc. Interprof. Desarro. Agrar. (AIDA) 2011, 1, 3-20.

8. Grymshi, D.; Crespo-Cebada, E.; Elghannam, A.; Mesías, F.j; Díaz-Caro, C. Understanding consumer attitudes towards ecolabeled food products: A latent class analysis regarding their purchasing motivations. Agribusiness 2021. [CrossRef]

9. Salinas, E.M.; Andrés, E.F. Influencia de las características demográficas y socioeconómicas de los consumidores en la compra de productos ecológicos. Estud. Sobre Consum. 2003, 65, 9-20.

10. Afonso, C.; Gavilán, D.; Gonçalves, H.M.; de Madariaga, J.G. Why consumers purchase organic products? The role of enviroment, health and age. In XXIX Congreso de Marketing AEMARK; Universidad de Sevilla: Sevilla, España, 2017; pp. 36-50.

11. Damalas, C.A.; Koutroubas, S.D. Farmers' training on pesticide use is associated with elevated safety behavior. Toxics $\mathbf{2 0 1 7}, 5,19$. [CrossRef]

12. Horrillo, A.; Gaspar, P.; Díaz-Caro, C.; Escribano, M. Análisis económico-estructural de explotaciones ganaderas ecológicas en dehesas y pastizales de Extremadura. Rev. Esp. Estud. Agrosoc. Pesq. 2020, 256, 133-171.

13. Horrillo, A.; Gaspar, P.; Díaz-Caro, C.; Escribano, M. A scenario-based analysis of the effect of carbon pricing on organic livestock farm performance: A case study of Spanish dehesas and rangelands. Sci. Total Environ. 2021, 751, 141675. [CrossRef]

14. Dessart, F.J.; Barreiro-Hurlé, J.; van Bavel, R. Behavioural factors affecting the adoption of sustainable farming practices: A policy-oriented review. Eur. Rev. Agric. Econ. 2019, 46, 417-471. [CrossRef]

15. Pearce, C.S.; Chen, D.M.; Liberacki, M.E.; Smallcomb, O.D. Promoting Alternatives to Harmful Pesticides on Small Farms Promoting Alternatives to Harmful Pesticides on Small Farms; Worcester Polytechnic Institute: New York, NY, USA, 2019.

16. Horrillo, A.; Escribano, M.; Mesias, F.J.; Elghannam, A.; Gaspar, P. Is there a future for organic production in high ecological value ecosystems? Agric. Syst. 2016, 143, 114-125. [CrossRef]

17. Schoonhoven, Y.; Runhaar, H. Conditions for the adoption of agro-ecological farming practices: A holistic framework illustrated with the case of almond farming in Andalusia. Int. J. Agric. Sustain. 2018, 16, 442-454. [CrossRef]

18. Hashemi, S.M.; Damalas, C.A. Farmers' perceptions of pesticide efficacy: Reflections on the importance of pest management practices adoption. J. Sustain. Agric. 2011, 35, 69-85. [CrossRef]

19. Robles, M.V.; Medel, R.R.; Toledo, J.U.; José, J.D. Adoption of conservation agriculture practices in Tlaxcala, Mexico. Rev. Mex. Cienc. Agric. 2016, 7, 3103-3113.

20. Ruysschaert, G.; Marchand, F.; Hijbeek, R. Assessing Farmers' Intention to Adopt Sustainable Management Practices for Soil Conservation Across Europe. In Proceedings of the 11th European IFSA Symposium, Berlin, Germany, 1-4 April 2014.

21. Kragt, M.E.; Dumbrell, N.P.; Blackmore, L. Motivations and barriers for Western Australian broad-acre farmers to adopt carbon farming. Environ. Sci. Policy 2017, 73, 115-123. [CrossRef]

22. Petrescu-Mag, R.M.; Banatean-Dunea, I.; Vesa, S.C.; Copacinschi, S.; Petrescu, D.C. What do Romanian farmers think about the effects of pesticides? Perceptions and willingness to pay for bio-pesticides. Sustainability 2019, 11, 3628. [CrossRef]

23. Sharifzadeh, M.S.; Abdollahzadeh, G.; Damalas, C.A.; Rezaei, R. Farmers' criteria for pesticide selection and use in the pest control process. Agriculture 2018, 8, 24. [CrossRef] 
24. Keulemans, W.; Bylemans, D.; de Coninck, B. Farming without Plant Protection Products: Can We Grow without Using Herbicides, Fungicides and Insecticides? Scientific Foresight Unit (STOA): European Parliament: Strasbourg, France, 2019.

25. Parra López, C.; Calatrava Requena, J. Factors related to the adoption of organic farming in Spanish olive orchards. Span. J. Agric. Res. 2005, 3, 5-16. [CrossRef]

26. Läpple, D.; Van Rensburg, T. Adoption of organic farming: Are there differences between early and late adoption? Ecol. Econ. 2011, 70, 1406-1414. [CrossRef]

27. Djokoto, J.J.; Owusu, V.; Awunyo-Vitor, D. Adoption of organic agriculture: Evidence from cocoa farming in Ghana. Cogent Food Agric. 2016, 2, 1242181. [CrossRef]

28. Ashari, N.F.N.; Sharifuddin, J.; Zainal Abidi, M. Factors determining organic farming adoption: International research results and lessons learned for Indonesia. Forum Penelit. Agro Ekon. 2017, 35, 45-58. [CrossRef]

29. Lohr, L.; Salomonson, L. Conversion subsidies for organic production: Results from Sweden and lessons for the United States. Agric. Econ. 2000, 22, 133-146. [CrossRef]

30. Pietola, K.S.; Lansink, A.O. Farmer response to policies promoting organic farming technologies in Finland. Eur. Rev. Agric. Econ. 2001, 28, 1-15. [CrossRef] 